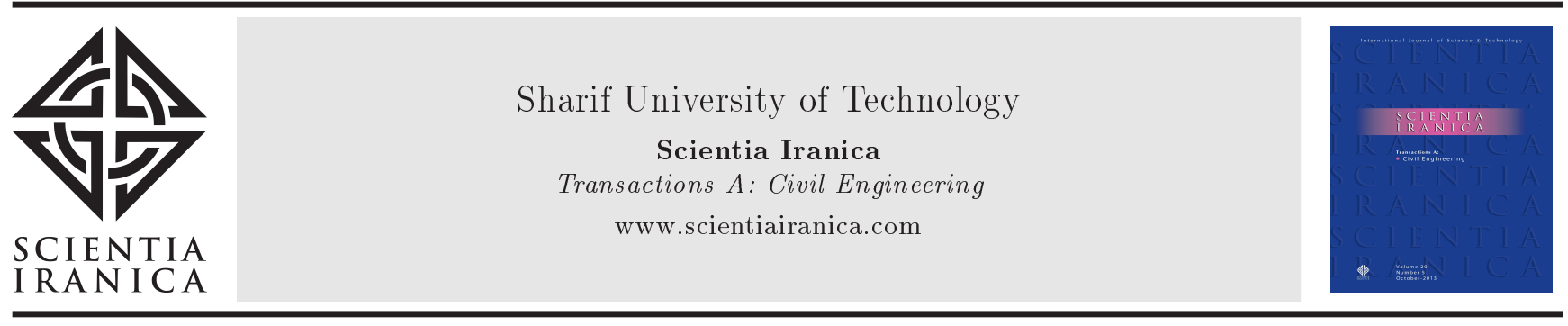

\title{
An adaptive relaxed cellular automata method for reliability-based hydropower operation of reservoirs
}

\author{
M. Azizipour* and M.H. Afshar \\ School of Civil Engineering, Iran University of Science and Technology, Tehran, Iran.
}

Received 5 December 2015; received in revised form 6 April 2016; accepted 18 June 2016

\section{KEYWORDS \\ Reliability; \\ Cellular automata; \\ Genetic algorithm; \\ Reservoir operation; \\ Hydropower.}

\begin{abstract}
This paper presents a novel cellular automata Approach as the solution to reliability-based reservoir hydropower operation problems. The method is based on the observation that a low value of the penalty parameter would lead to partial enforcement of the constraints. Therefore, in this method, the constraints of the chance-constrained operation problem, namely operational and reliability constraints, are dealt with differently. A high enough value of the penalty parameter is used for the first set while a lower than enough value is used for the second set, leading to strong enforcement of the first set of the constraint and partial fulfillment of the second set. Since the proper value of the penalty parameter to be used for the reliability constraints is not known a priori, an adaptive method is proposed to find the proper value. The proposed model is used for operation of Dez reservoir in Iran and the results are presented and compared with those of a Genetic Algorithm. Hydropower operation is considered over short, medium, and long-term periods to demonstrate the efficiency and effectiveness of the proposed method for problems of different scales. The proposed model has proven to produce results superior to the results of GA with much reduced computational effort.
\end{abstract}

(C) 2017 Sharif University of Technology. All rights reserved.

\section{Introduction}

The growth of population in recent decades has led to the increased development and construction of hydropower projects. Optimal use of water to produce power from an available hydropower plant is an important issue. Many attempts have been made by researchers to achieve the best possible performance of the reservoir system to produce firm energy. Various optimization techniques have been used for optimal reservoir operation represented by a set of releases or storages. Nonlinear programming (NLP) has been widely used to solve diverse reservoir operation prob-

*. Corresponding author. Tel.: +1 530 219-7507

E-mail addresses: m_azizipour@iust.ac.ir (M. Azizipour); mhafshar@iust.ac.ir (M.H. Afshar)

doi: $10.24200 /$ sci. 2017.4151 lems with various objectives [1,2]. An improved Dynamic Programming (DP) has been proposed for hydropower operation [3]. A Dynamic ProgrammingLinear Programming (DP-LP) algorithm was proposed in [4] for optimization of multi-reservoir hydropower systems operation. An extensive review of DP applicability and limitations was presented in [5]. Stochastic Dynamic Programming (SDP) has also been used for solving reservoir operation problems considering uncertainty of the inflow to the reservoirs [6-8].

In the last decade, Evolutionary Algorithms (EA) have been introduced and widely used to optimize reservoir operation. Many different forms of reservoir operation problems have been solved by genetic algorithm [9-12]. Ant Colony Optimization (ACO) [13,14], Particle Swarm Optimization (PSO) [15], Simulated Annealing (SA) [16,17], and Honey Bees Mating Optimization (HBMO) [18] have also been suggested and used to achieve optimal operating policies for reservoir 
systems. A comprehensive survey of the use of EAs can be found in [19]. Recently, Afshar and Shahidi [20] used a Cellular Automata (CA) method for largescale optimal operation of single reservoirs, concluding that CA outperformed heuristic search methods to find near optimal solution in much less computational time. The method was later extended for multi-reservoir systems with the same findings that CA could yield better solution than heuristic search methods could with much reduced computational time [20]. None of these studies, however, have considered the reliability of reservoir operation.

While all the above-mentioned approaches were used for optimal operation of reservoirs disregarding the importance of reliability, some researchers proposed methods to solve chance-constrained reservoir management problems, which included one or more probabilistic constraints. Askew [21] used SDP to derive optimum reservoir operating policy considering reliability constraints. A DP procedure was developed in [22] to solve reliability-constrained reservoir operation problems. Simonovic and Marino [23] proposed a three-level solution algorithm for a multipurpose reservoir and solved reservoir management problem by reliability programming. A reliability programming technique was introduced for multiple-multipurpose reservoir system [24]. Marino and Mohammadi [25] applied a model based on Chance-Constrained Linear Programming (CCLP) and DP to determine the optimum monthly releases from a multipurpose reservoir. Sreenivasan and Vedula [26] used CCLP formulation for a multipurpose reservoir to determine the maximum annual hydropower produced while meeting irrigation demand at a specified reliability.

In this study, a novel Relaxed Cellular Automata (RCA) method is developed to determine optimal hydropower operating policy of a single reservoir for a specified reliability. In the proposed method, the constraints of the operation problem, namely operational and reliability constraints, are enforced differently. A high enough value of the penalty parameter is used for the operational constraints while a lower than enough value is used for the reliability constraints, leading to full enforcement of the first set and partial fulfillment of the second set. In this way, the satisfaction of the reliability constraints is relaxed compared to the operational constraints and, hence, the use of the term relaxed cellular automata. Since the proper value of the penalty parameter to be used for the reliability constraints is not known a priori, an adaptive method is proposed to find the proper value. For this, the problem is first solved for the optimal operation using a zero value of the penalty parameter. The value of the penalty parameter is then adjusted using the reliability of the optimal operation obtained. At each iteration, the penalty parameter increases if the current reliability is less than the target reliability and decreases otherwise. The proposed model is used for optimal hydropower operation of Dez reservoir in Iran and the results are presented and compared with those of the GA. The short, medium, and long-term hydropower operations are considered to demonstrate efficiency and effectiveness of the proposed method for hydropower operation problems of different scales. The model is shown to be superior to the GA in any regards such as computational effort and optimality of the final solution.

\section{Chance constrained hydropower operation of a single reservoir}

The single-objective operation of reservoirs can be either benefit-based or reliability-based. In a benefitbased operation, the reservoir is operated such that the net benefit of the operation is maximized while the reliability-based operation is concerned with maximizing the reliability of meeting a set of pre-defined demands over the operation period. While simultaneous consideration of benefit and reliability requires the use of bi-objective optimization methods, a simpler and more practical problem is often encountered in which predefined target reliability is to be met in a benefit-based reservoir operation. In these problems, commonly referred to as chance-constrained reservoir operation problems, the objective is to find a set of releases, or storages, such that a predefined pattern of demands, water or energy, is observed with a predefined reliability while optimizing the objective function over the operation period. Different operational policies represented by different objectives are defined and used for operation of single or multi-reservoir systems.

Here, the chance-constrained hydropower operation of a single reservoir is defined by an operation policy that minimizes the total positive deviation of the produced power from the total capacity of hydroelectric plant $(\mathrm{TCH})$ defined as:

$$
\operatorname{Min} F=\sum_{t=1}^{N}\left(1-\frac{P_{t}}{\mathrm{TCH}}\right) \quad t=1, \ldots, N,
$$

subject to:

$$
\begin{aligned}
& S_{t+1}=S_{t}+Q_{t}-R_{t}-L_{t} \quad t=1, \ldots, N, \\
& S_{\min } \leq S_{t} \leq S_{\max } \quad t=1, \ldots, N+1, \\
& R_{\min } \leq R_{t} \leq R_{\max } \quad t=1, \ldots, N, \\
& \operatorname{Pr}[P \geq \mathrm{TCH}] \geq R_{T},
\end{aligned}
$$

where $R_{t}, S_{t}, L_{t}$, and $Q_{t}$ are water release from reservoir, water storage, evaporation losses, and inflow to reservoir at period $t$, all in Million Cubic 
Meters (MCM), respectively; $N$ is the total number of operation periods; $S_{\min }$ and $S_{\max }$ are minimum and maximum allowable reservoir storage, respectively; $R_{\min }$ and $R_{\max }$ are minimum and maximum water release from reservoir, respectively; and $R_{T}$ is the target reliability. Here, $P_{t}$ is the power generated by the hydroelectric plant at period $t$ (MW); other parameters were defined earlier. The power produced by the plant is calculated by:

$$
P_{t}=\min \left\{\left(\frac{g e}{1000 \times \mathrm{PF} \times \text { Coef }}\right) \times\left(R_{t} H_{t}\right), \mathrm{TCH}\right\} .
$$

with:

$$
H_{t}=\left(\frac{E_{t}+E_{t+1}}{2}\right)-E_{T}
$$

where $g$ is gravity acceleration, $e$ is efficiency of the hydroelectric plant, $\mathrm{PF}$ is the Plant Factor, $H_{t}$ is the effective head of hydroelectric plant, $E_{t}$ is the elevation of water in reservoir at period $t$; Coef is a coefficient that converts the release volume to discharge, and $E_{T}$ is the tail water elevation of hydroelectric plant. The elevation of water in reservoir at any period could be calculated from volume-elevation curve of the reservoir. Here, a volume-elevation curve in the form of:

$$
E_{t}=a \times S_{t}^{3}+b \times S_{t}^{2}+c \times S_{t}+d,
$$

is used where $a, b, c$, and $d$ are constant coefficients obtained by fitting Eq. (8) to the available data.

\section{Cellular automata}

The theory of CA as a self-reproducing model was first developed during the 1950s by Stan Ulam [27]. Thatcher [28], Codd [29], and Burks [30] as well as other researchers made their own contributions to the method, leading to the presentation of $\mathrm{CA}$ as a global simulation method. $\mathrm{CA}$ has been used to model different problems such as pollutants dispersion in the atmosphere [31], heat flow [32], absorptiondesorption phenomenon [33], inter-diffusion of atoms of two materials [34], the solidification process [35], and drug therapies for HIV infection [36]. Chen et al. [37] focused on the development and application of CA approach for ecological and ecohydraulics modeling. Li et al. [38] developed an integrated model, which combined a two-dimensional hydrodynamic module with a vegetation evolution module and a fish habitat module. They used an unstructured $\mathrm{CA}$ in the vegetation module. Ghimire et al. [39] used two-dimensional CA for flood modeling. Austin et al. [40] presented an efficient and accurate conceptual CA-based simulator for sewer networks simulation. Sanchez et al. [41] proposed an integrated cellular automata evolutionarybased approach to derive a drainage network layout based on future land use scenarios.

While CA was originally proposed as a simulation method to reproduce complex processes, it is now being widely used to solve optimization problems of different engineering disciplines due to its interesting features such as simplicity and computational speed.

$\mathrm{CA}$, as an optimization technique, has been first used in structural optimization. Kita and Toyoda [42] used CA for shape and topology optimization of continuum structures. Tatting and Gurdal [43] employed CA for design of 2D structures. Afshar and Faramarzi [44] used CA for size optimization of some truss structures and compared the results with those of Fully Stressed Design (FSD) method and showed that CA was more efficient than FSD. Faramarzi and Afshar [45] proposed a hybrid CA-LP method for size optimization of truss structures. The optimization problem was recast in terms of the nodal displacement and internal forces and iteratively solved in two phases. In the first phase, the nodal displacements of the structure were obtained using a CA approach while the internal forces were determined in the second phase by an LP method. Farmarzi and Afshar [46] extended the CA-LP method for simultaneous size and topology optimization of truss structures. The optimization problem was solved in two phases. The optimal topology of structures was obtained in the first phase and the optimal sizing of structure was carried out in the second phase using the CA-LP method of Faramarzi and Afshar [45].

The first application of the CA to water resources problem was proposed by Keedwell and Khu [47], in which a CA was used to produce initial solutions for a GA model for optimal design of water distribution network. Guo et al. [48] hybridized a Non-dominated Sorting GA (NSGAII) with CA and used it for multiobjective design of both water distribution and storm sewer networks. The first use of CA as a stand-alone optimizer in water resources problems was by Guo et al. [49] who proposed a CA model for the optimal design of storm-sewer networks with the objective of minimizing the capital cost of the sewer network and total flooding volume in the system. While most of the research used an ad-hoc transition rule based on engineering judgments and physical characteristics of the considered problem, Afshar and Shahidi [20] were the first to propose a CA model with a mathematically derived transition rule and used it as optimal solution to reservoir operation problems. More recently, Afshar [50] extended the model of Afshar and Shahidi [20] for optimal hydropower operation of multi-reservoir systems. The objective function and constraints of problem were projected on each cell to derive the transition rule represented by an optimization sub- 
problem on each period, which was solved using an NLP solver. The method was used for solving the wellknown four-reservoir and ten-reservoir problems and the results were compared with those obtained by GA and PSO methods, indicating superiority of the method to heuristic search methods.

Application of $\mathrm{CA}$ with mathematically derived transition rule for optimal design of sewer networks was first introduced in [51]. The nodes of the network were used as CA cells with the corresponding elevation as cell states. Afshar and Rohani [52] extended the method of Afshar et al. [51] to a hybrid two-stage CA method for optimal design of sewer networks. The problem of optimal design of sewer network was decomposed into two sub-optimization problems for nodal cover depths and pipe diameters of the network, which were both solved using CA method. Comparison of the results with those obtained by GA, PSO, and ACO demonstrated the efficiency and effectiveness of the proposed hybrid method.

\section{Proposed Adaptive Relaxed Cellular Automata (ARCA) method}

The optimization problem in hand, chance-constrained hydropower operation of a single reservoir, contains two sets of constraints of different nature. The operational constraints, represented by Eqs. (2)-(4) and (6)-(8), are of explicit nature and, therefore, can be easily enforced while searching for the optimal solution. However, the reliability constraint, represented by Eq. (5), is of implicit type and its imposition requires an iterative method. The first step for the application of CA to reliable reservoir operation problem is to recast the reliability constraints into more explicit form for easier handling. Defining $A^{\prime}$ as a subset of $A=\{1,2,3, \ldots, N\}$ with $N^{\prime}$ members, the reliability constraint is written as:

$$
P_{t} \geq \mathrm{TCH}, t \in A^{\prime} \text {. }
$$

subject to the condition that $N^{\prime}$ is equal to or greater than $N * R_{T}$, where $N^{\prime}$ represents the total number of periods for which the corresponding reliability constraints are realized ensuring an operation of desired target reliability, $R_{T}$. The reliability constraint defined by Eq. (9) is now in more useful form for the application of CA as it is explicitly defined in terms of the reservoir release as the decision variable of the problem.

The second step for the application of CA to the problem in hand is to recast the problem into an unconstrained optimization problem. For this, a penalty method is used in which the constraints of problem are embedded into the objective function. This leads to the following unconstrained optimization problem defined as:

$$
\operatorname{Min} \mathrm{PF}=F+\alpha \times \sum_{t=1}^{N}\left(\mathrm{CV}_{o}\right)_{t}^{2}+\beta \times \sum_{t=1}^{N}\left(\mathrm{CV}_{R}\right)_{t}^{2},
$$

where $F$ stands for the original objective function, $\mathrm{PF}$ is the penalized objective function of the problem, $\left(\mathrm{CV}_{o}\right)_{t}$ represents the violation of operational constraints defined as:

$$
\left(\mathrm{CV}_{o}\right)_{j}=\max \left\{\left(\mathrm{CV}_{o 1}\right)_{j},\left(\mathrm{CV}_{o 2}\right)_{j},\left(\mathrm{CV}_{o 3}\right)_{j},\left(\mathrm{CV}_{o 4}\right)_{j}\right\} .
$$

With:

$$
\begin{aligned}
& \left(\mathrm{CV}_{o 1}\right)_{j}=\max \left\{\left(S_{j}-S_{\max }\right), 0.0\right\} \\
& \left(\mathrm{CV}_{o 2}\right)_{j}=\max \left\{\left(S_{\min }-S_{j}\right), 0.0\right\} \\
& \left(\mathrm{CV}_{o 3}\right)_{j}=\max \left\{\left(R_{j}-R_{\max }\right), 0.0\right\} \\
& \left(\mathrm{CV}_{o 4}\right)_{j}=\max \left\{\left(R_{\min }-R_{j}\right), 0.0\right\}
\end{aligned}
$$

$\left(\mathrm{CV}_{R}\right)_{j}$ is the violation of reliability constraint defined as:

$$
\left(\mathrm{CV}_{R}\right)_{j}=\max \left\{\left(\mathrm{TCH}-P_{j}\right), 0.0\right\},
$$

and $\alpha$ and $\beta$ are penalty coefficients for operational and reliability constraints, respectively.

Application of $\mathrm{CA}$ to any optimization problem requires four primary components of the $\mathrm{CA}$ model, namely, cells, cell state, cell neighborhood, and the transition or updating rule, to be defined. For the operation problem in hand, the cells are taken as discrete points in time representing the beginning and the end of each period of the operation. Therefore, the cell state, representing the decision variables of the optimization problem, is taken as the reservoir storage at these discrete points. The surrounding cells are considered as the neighborhood cells. A schematic representation of cell neighborhood is illustrated in Figure 1 as used in [20].

The transition rule for an arbitrary cell, $j$, is derived by requiring that the problem objective function (Eq. (10)) should be minimized with respect to the cell state, $S_{j}$, while all other cell states are kept constant. Assuming pre-defined arbitrary initial values

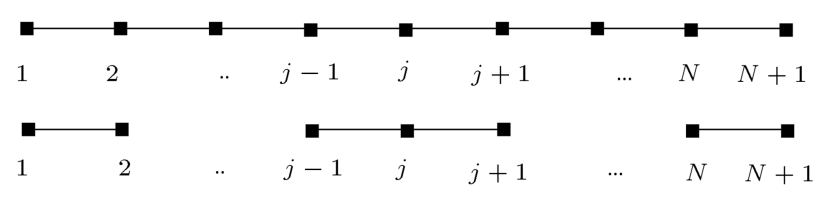

(a)

(b)

(c)

Figure 1. Schematic representation of internal and boundary cells with their neighborhoods: (a) Left boundary cell, (b) internal cell, and (c) right boundary cell. 
for all cell states denoted by $S_{j}^{k}, j=1,2, \ldots, N$, the updated value of the $j$ th cell state $S_{j}^{k+1}$ is obtained by solving the following sub-optimization problem defined on the neighborhood of cell $j$ for hydropower operation problem:

$$
\begin{aligned}
\operatorname{Min}(\mathrm{PF})_{j}= & \left(\mathrm{TCH}-P_{j-1}^{k+1}\right)^{2}+\left(\mathrm{TCH}-P_{j}^{k+1}\right)^{2} \\
& +\alpha \times\left[\left(\mathrm{CV}_{O}\right)_{j-1}^{2}+\left(\mathrm{CV}_{O}\right)_{j}^{2}\right]^{k+1}+\beta \\
& \times\left[\left(\mathrm{CV}_{R}\right)_{j-1}^{2}+\left(\mathrm{CV}_{R}\right)_{j}^{2}\right]^{k+1}
\end{aligned}
$$

Here, $P_{j-1}^{k+1}$ and $P_{j}^{k+1}$ are the updated values of power at periods $j-1$ and $j$, respectively.

Rewriting Eq. (11) in terms of $\Delta S_{j}=S_{j}^{k+1}-S_{j}^{k}$ and its analytical solution leads to the updating rule, as shown in Box I, with:

$$
\begin{aligned}
\frac{\partial P_{j-1}}{\partial S_{j}}= & \left(\frac{g e}{1000 \times \times \mathrm{PF} \times \text { Coef }}\right) \times\left(\frac{\partial R_{j-1}}{\partial S_{j}} H_{j-1}\right. \\
& \left.+\frac{\partial H_{j-1}}{\partial S_{j}} R_{j-1}\right)
\end{aligned}
$$

$\frac{\partial P_{j}}{\partial S_{j}}=\left(\frac{g e}{1000 \times \times \mathrm{PF} \times \text { Coef }}\right)$

$$
\times\left(\frac{\partial R_{j}}{\partial S_{j}} H_{j}+\frac{\partial H_{j}}{\partial S_{j}} R_{j}\right)
$$

$$
\frac{\partial H_{j}}{\partial S_{j}}=\frac{1}{2}\left(\frac{\partial E_{j}}{\partial S_{j}}\right)=\frac{1}{2} \times\left(3 a S_{j}^{2}+2 b S_{j}+C\right)
$$

$\lambda_{j}=\left(\frac{1000 \times \mathrm{PF} \times \text { Coef } \times \mathrm{TCH}}{g \times e}\right)$

$$
\times\left(\frac{-d H_{j} / d s_{j}}{H_{j}^{2}}\right),
$$

where $B_{O}$ and $B_{R}$ are binary variables with zero values if the solution at iteration $k$ is feasible regarding operational and reliability constraints, respectively, and with unit values otherwise.

It is a well-known fact that the value of the penalty coefficient in the penalty method determines the level of constraint satisfaction. With a zero value for the penalty coefficient, the constraints would not be taken into account as if an unconstrained problem is solved. With a large enough value of the penalty parameter, for which any infeasible solution has a total cost greater than any feasible solution, the constraints are totally enforced. For any value between zero and large enough value of the penalty parameter, the constraints are partially enforced depending on how close the penalty parameter is to the proper value. This means that assuming a proper value for the operational penalty parameter, $\alpha$, and a zero value for the reliability penalty parameter, $\beta$, would lead to an operationally feasible solution with the reliability constraint totally disregarded. Increasing the value of the reliability penalty parameter, $\beta$, would logically lead to operationally feasible solutions of higher reliability. To assess the effect of the reliability penalty parameter on the reliability of the final solution, a series of experiments are carried out for the case of operation over 60 months of the test case used by [20] with a fixed value of $\alpha=100$ and the results are produced in Table 1.

It is seen that increasing the reliability penalty coefficient, $\beta$, leads to solutions of higher reliability as expected while a zero value of the parameter leads to solutions in which no reliability constraints are considered. This experiment suggests that the penalty parameter, $\beta$, could gradually increase until the desired target reliability is reached. This process, however, could be time consuming since no prior knowledge of the proper magnitude of the penalty coefficient is in hand.

An adaptive method is, therefore, proposed to find the proper value of the reliability penalty parameter, $\beta$. Having fixed the operational penalty parameter

$$
\begin{aligned}
\Delta S_{j}= & \frac{1}{\left(\frac{\partial P_{j-1}}{\partial S_{j}}\right)^{2}+\left(\frac{\partial P_{j}}{\partial S_{j}}\right)^{2}+\alpha \times\left[\left(B_{o}\right)_{j-1}+\left(B_{o}\right)_{j}\right]+\beta \times\left[\left(B_{R}\right)_{j-1} \times \lambda_{j-1}+\left(B_{R}\right)_{j} \times \lambda_{j}\right]} \\
& \times\left\{\frac{\partial P_{j-1}}{\partial S_{j}}\left(\mathrm{TCH}-P_{j-1}^{k}\right)+\frac{\partial P_{j}}{\partial S_{j}}\left(\mathrm{TCH}-P_{j}^{k}\right)+\alpha \times\left[\left(\mathrm{CV}_{o}\right)_{j-1}+\left(\mathrm{CV}_{o}\right)_{j}\right]^{k}+\beta\right. \\
& \left.\times\left[\left(\mathrm{CV}_{R}\right)_{j-1}+\left(\mathrm{CV}_{R}\right)_{j}\right]^{k}\right\}
\end{aligned}
$$


Table 1. The effect of reliability penalty parameter on the reliability of the operation.

\begin{tabular}{|c|c|c|c|}
\hline \multicolumn{2}{|c|}{ Without evaporation losses } & \multicolumn{2}{|c|}{ With evaporation losses } \\
\hline$\beta$ & Reliability & $\beta$ & Reliability \\
\hline 0.0 & 0.25 & 0.0 & 0.23 \\
\hline 0.2 & 0.25 & 0.2 & 0.32 \\
\hline 0.4 & 0.30 & 0.4 & 0.32 \\
\hline 0.6 & 0.35 & 0.6 & 0.43 \\
\hline 0.8 & 0.61 & 0.8 & 0.48 \\
\hline
\end{tabular}

value, the problem is first solved using a zero value of the penalty coefficient, $\beta$, leading to a solution with a reliability, $R$, lower than the target reliability, $R_{T}$. At each iteration, the penalty coefficient is adjusted using the following relation:

$$
\beta^{\text {new }}=\left[\beta^{\text {old }}+\left(R_{T}-R^{\text {old }}\right)\right]
$$

where $R^{\text {old }}$ is the reliability of the solution obtained using the previous value of the reliability penalty parameter $\beta^{\text {old }}$. For a penalty coefficient less than proper value, the reliability of the solution $R^{\text {old }}$ is less than the target reliability, leading to an increase in the updated value of the penalty parameter $\beta^{\text {new }}$ and vice-versa. The iterative process of updating is continued until the current reliability is equal to the target reliability.

\section{Model application and results}

In this section, efficiency and effectiveness of the proposed model are illustrated for chance-constrained hydropower operation of "Dez" reservoir in the southern district of Iran. To assess the effect of the problem scale on the performance of the model, three different operation periods of 5,20 , and 40 years are considered here for two cases of with and without evaporation losses. The average annual inflow to the reservoir is estimated at $5900 \mathrm{MCM}$. The active storage volume of reservoir is $2510 \mathrm{MCM}$. The minimum and maximum admissible storage volumes are 830 and 3340 MCM, respectively, while maximum and minimum water release volumes are considered to be $1000 \mathrm{MCM}$ and 0 , respectively. The coefficients of volume-elevation curve defined by Eq. (8) are taken $a=249.833, b=0.05872$, $c=-1.37^{*} 10^{-5}$, and $d=1.526 * 10^{-9}$. The plant factor of hydroelectric plant is 0.417 , its efficiency is $90 \%$, and the tail water elevation of hydropower plant is $172 \mathrm{~m}$.

The proposed ARCA model is used to solve the chance-constrained hydropower operation of Dez reservoir over three different operation periods with different target reliabilities for both cases of with and without evaporation losses. Table 2 presents the solution cost, CPU time, reliability of the solution obtained by the proposed model, number of adaptive iterations required, and the final value of the operational penalty parameter, $\beta$, for different target reliabilities of hydropower operation without evaporation losses. It is seen that the proposed method generally converges in a few iterations and, therefore, it is able to find the optimal solution within few seconds, illustrating the efficiency of the proposed method for the problem. Figures 2-4 show the evolution of the reliability penalty parameter during the adaptive process starting with a

Table 2. Results of hydropower operation for periods of 60, 240, and 480 months without evaporation losses.

\begin{tabular}{ccccccc}
\hline Months & $\begin{array}{c}\text { Target } \\
\text { reliability }\end{array}$ & $\begin{array}{c}\text { Solution } \\
\text { cost }\end{array}$ & $\begin{array}{c}\text { Computational } \\
\text { time (sec) }\end{array}$ & Reliability & $\begin{array}{c}\text { No. of } \\
\text { iterations }\end{array}$ & $\begin{array}{c}\text { Final penalty } \\
\text { coefficient }\end{array}$ \\
\hline \multirow{2}{*}{60} & 0.6 & 7.41 & 0.16 & 0.6 & 6 & 0.75 \\
& 0.65 & 7.39 & 0.18 & 0.65 & 14 & 1.03 \\
& 0.7 & 7.38 & 0.22 & 0.7 & 27 & 1.47 \\
240 & 0.6 & 21.21 & 1.39 & 0.6 & 7 & 0.27 \\
& 0.65 & 20.89 & 1.32 & 0.6 & 13 & 0.43 \\
& 0.7 & 20.76 & 1.24 & 0.7 & 16 & 0.63 \\
& & & & & & \\
& 0.6 & 45.99 & 2.44 & 0.6 & 10 & 0.44 \\
& 0.65 & 45.71 & 2.15 & 0.65 & 14 & 0.62 \\
& 0.7 & 45.55 & 2.1 & 0.7 & 22 & 0.86 \\
\hline
\end{tabular}




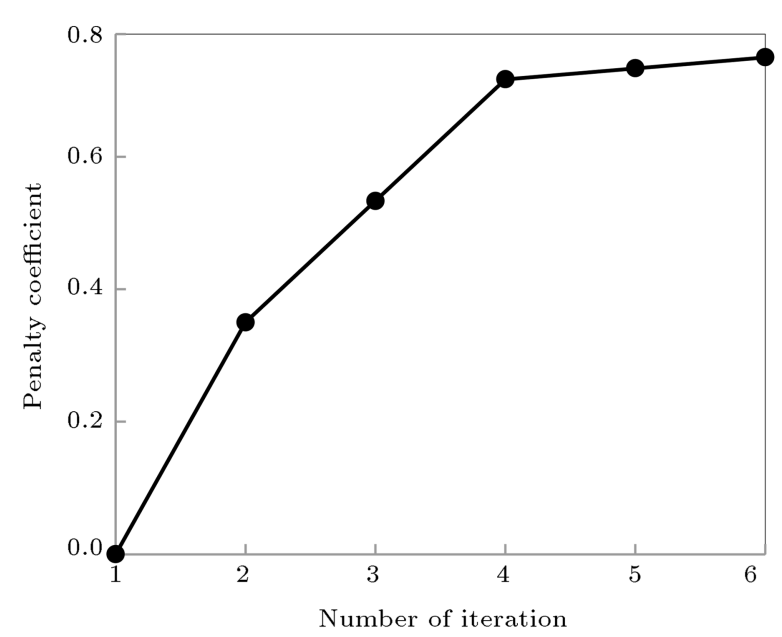

Figure 2. Evolution of reliability penalty coefficient for hydropower operation, without evaporation losses, over 60 months with target reliability of 0.6 .

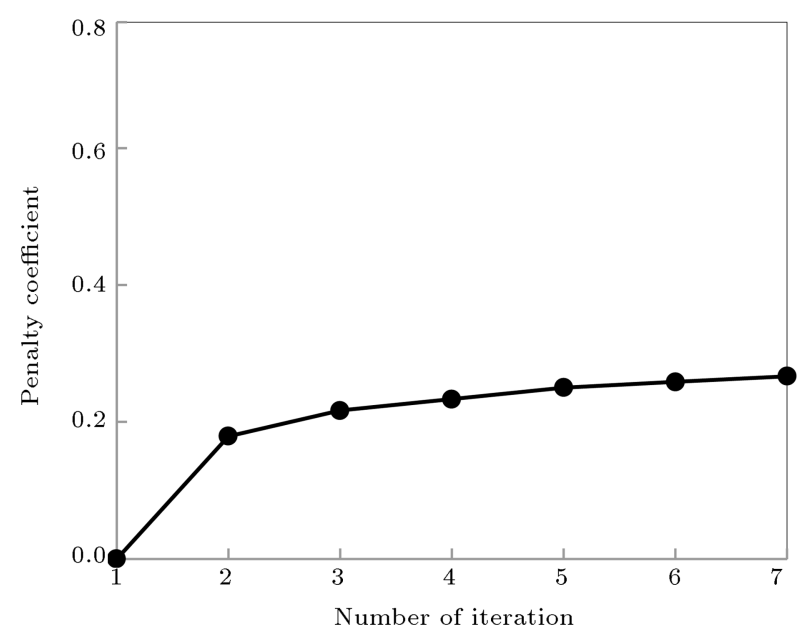

Figure 3. Evolution of reliability penalty coefficient for hydropower operation, without evaporation losses, over 240 months with target reliability of 0.6 .

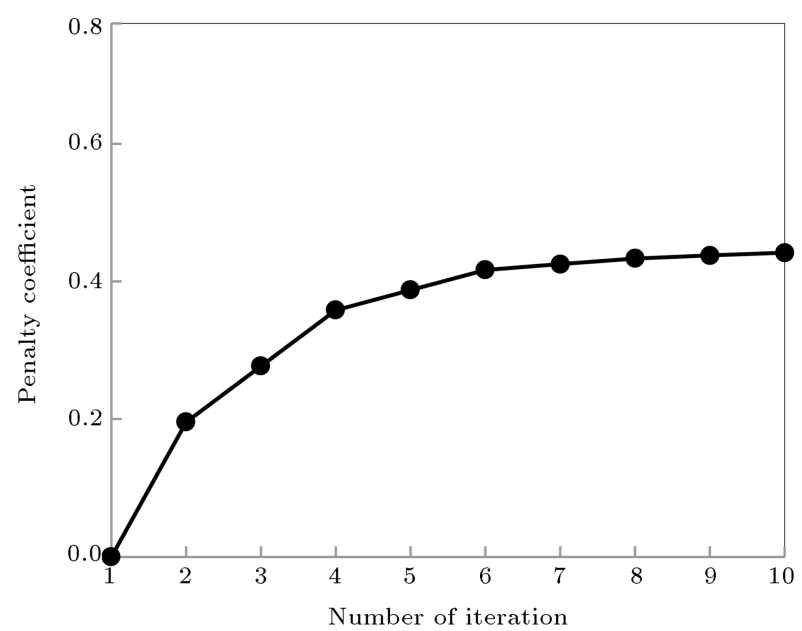

Figure 4. Evolution of reliability penalty coefficient for hydropower operation, without evaporation losses, over 480 months with target reliability of 0.6 . zero value leading to solution reliabilities of $0.25,0.42$, and 0.4 at the start of iterative process for operation periods of 60,240 , and 480 months, respectively. In all cases, the penalty parameter is seen to rise from the initial value of zero to the final value in a few iterations before the final fine tuning of the penalty parameter. The monthly produced power over 60 months with target reliability of 0.7 for the case of disregarding evaporation losses is presented in Figure 5.

The results of the proposed ARCA model for hydropower operation of Dez reservoir, considering evaporation losses, over different operation periods and target reliabilities are shown in Table 3. Evolution of the reliability penalty parameter during the iterative process for hydropower operation is shown in Figures 6-8, starting with a zero value leading to solution reliabilities of $0.23,0.39$, and 0.39 at the start of iterative process for operation periods of 60,240 , and 480 months, respectively. Figure 9 shows the monthly produced power for the case of operation over 60 months and target reliability of 0.7 .

The problem under consideration is also solved here using a real-coded GA model, in which the storage volumes are considered as the decision variables. A sensitivity analysis was carried out to determine the proper values of the GA parameters. As a result, a tournament selection with random tournament size, a single-point crossover with probability of 1 and random weighted averaging after the crossover site, and a 1bit mutation procedure with probability of $1 / l$, with $l$ being the length of individual chromosome, are used to produce the off-springs. Population size is set at 50, 100 , and 200 for operation periods of 60,240 , and 480 months, respectively, and exhaustive maximum numbers of generations equal to 30000, 60000, and 90000

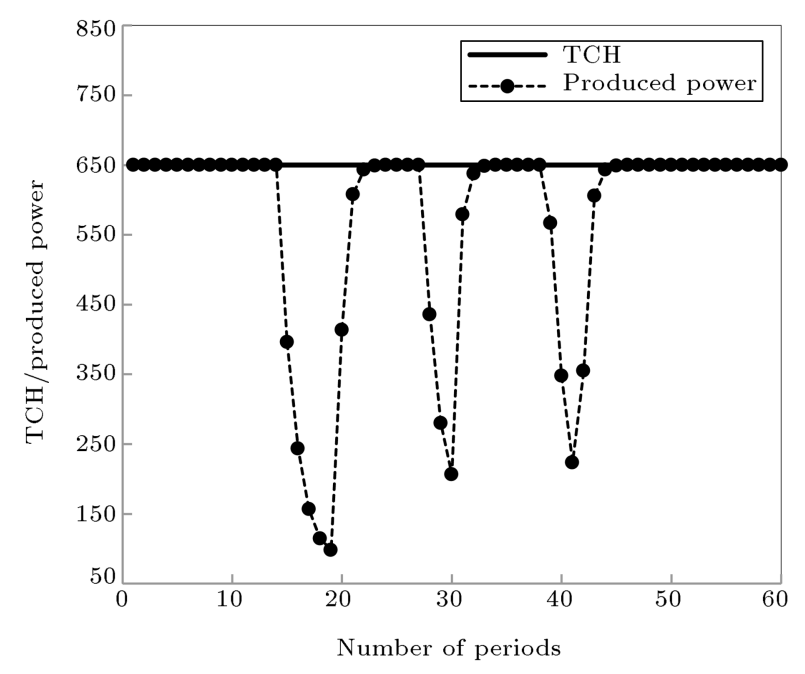

Figure 5. Monthly produced optimum power resulting from ARCA for hydropower operation, without evaporation losses, over 60 months with target reliability of 0.7 . 
Table 3. Results of hydropower operation for periods of 60, 240, and 480 months with evaporation losses.

\begin{tabular}{ccccccc}
\hline Months & $\begin{array}{c}\text { Target } \\
\text { reliability }\end{array}$ & $\begin{array}{c}\text { Solution } \\
\text { cost }\end{array}$ & $\begin{array}{c}\text { Computational } \\
\text { time (sec) }\end{array}$ & Reliability & $\begin{array}{c}\text { No. of } \\
\text { iterations }\end{array}$ & $\begin{array}{c}\text { Final penalty } \\
\text { coefficient }\end{array}$ \\
\hline \multirow{2}{*}{60} & 0.6 & 9.19 & 0.68 & 0.6 & 9 & 0.93 \\
& 0.65 & 9.18 & 0.72 & 0.65 & 15 & 1.27 \\
& 0.7 & 9.18 & 0.41 & 0.7 & 31 & 1.92 \\
240 & 0.6 & 25.97 & 3.15 & 0.6 & 11 & 0.43 \\
& 0.65 & 25.84 & 2.67 & 0.6 & 11 & 0.60 \\
& 0.7 & 25.80 & 2.57 & 0.7 & 20 & 0.85 \\
& & & & & & \\
& 0.6 & 56.72 & 7.59 & 0.6 & 14 & 0.58 \\
& 0.65 & 56.58 & 7.31 & 0.65 & 11 & 0.77 \\
& 0.7 & 56.51 & 5.25 & 0.7 & 23 & 1.07 \\
\hline
\end{tabular}

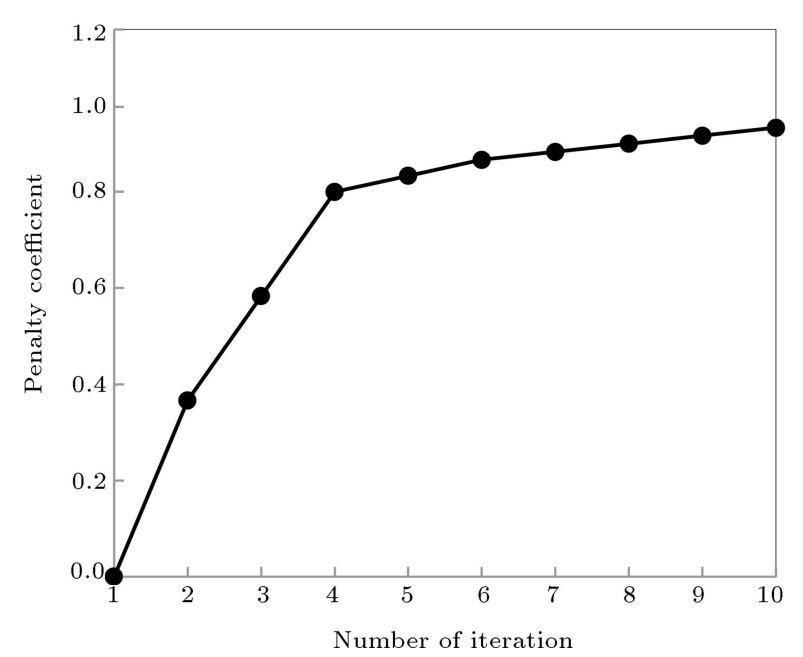

Figure 6. Evolution of reliability penalty coefficient for hydropower operation, with evaporation losses, over 60 months with target reliability of 0.6 .

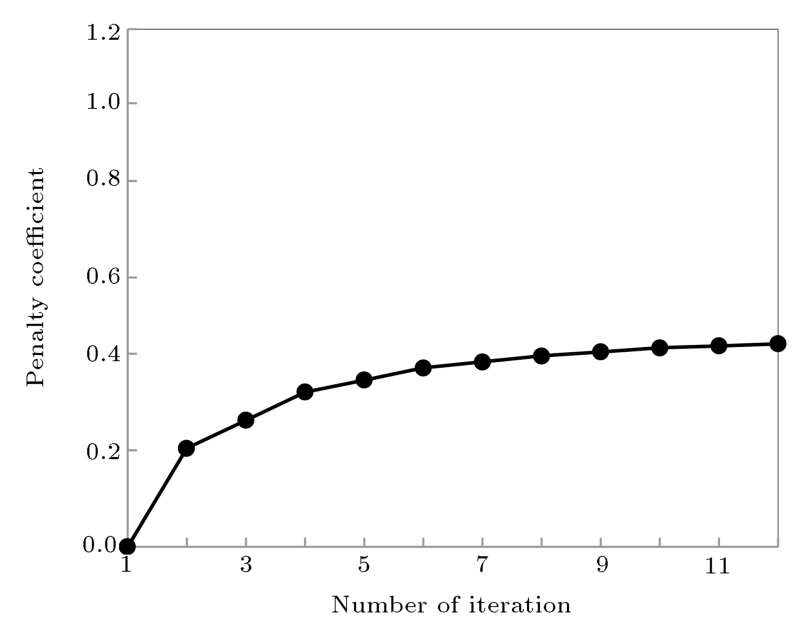

Figure 7. Evolution of reliability penalty coefficient for hydropower operation, with evaporation losses, over 240 months with target reliability of 0.6 .

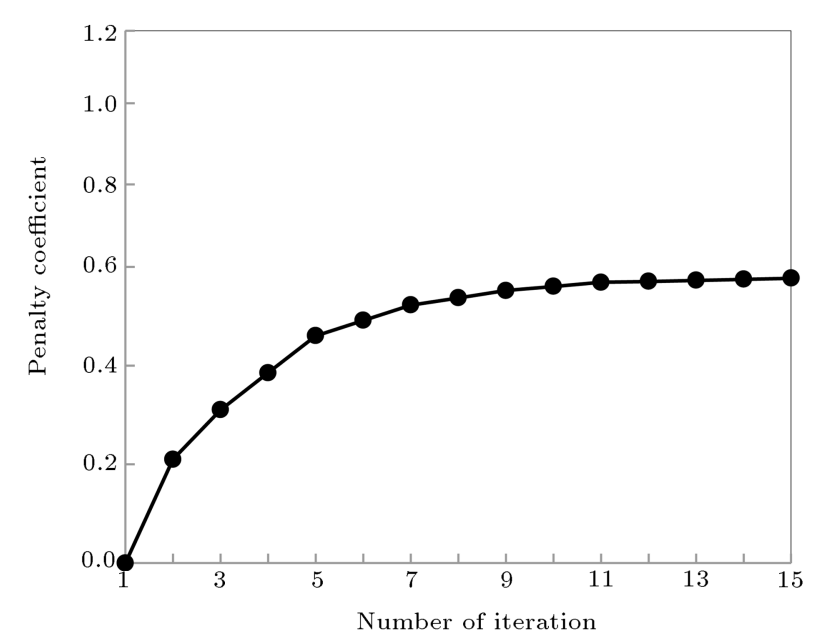

Figure 8. Evolution of reliability penalty coefficient for hydropower operation, with evaporation losses, over 480 months with target reliability of 0.6.

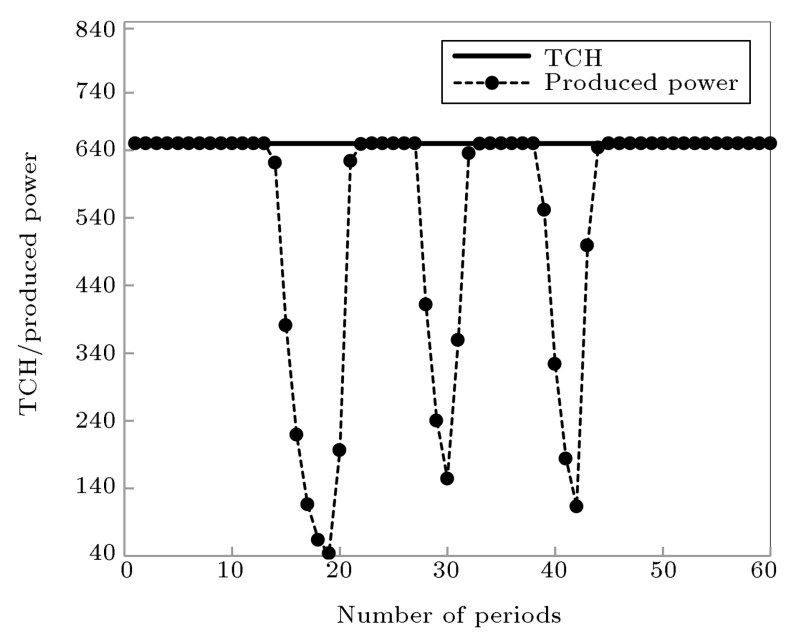

Figure 9. Monthly produced optimum power resulting from ARCA for hydropower operation, with evaporation losses, over 60 months with target reliability of 0.7 . 
Table 4. Results of GA for hydropower operation, without evaporation losses, for periods of 60, 240, and 480 months.

\begin{tabular}{|c|c|c|c|c|c|c|c|}
\hline \multirow{2}{*}{$\begin{array}{l}\text { Operation } \\
\text { period }\end{array}$} & \multirow{2}{*}{$\begin{array}{c}\text { Target } \\
\text { reliability }\end{array}$} & \multirow[t]{2}{*}{ Generation } & \multicolumn{3}{|c|}{ Total cost } & \multirow[t]{2}{*}{ SD } & \multirow{2}{*}{$\begin{array}{c}\text { Average computation } \\
\text { time (sec) }\end{array}$} \\
\hline & & & Minimum & Maximum & Average & & \\
\hline \multirow{9}{*}{60} & \multirow{3}{*}{0.6} & 20000 & 7.73 & 9.34 & 8.54 & 0.47 & 171 \\
\hline & & 25000 & 7.72 & 8.92 & 8.40 & 0.60 & 214 \\
\hline & & 30000 & 7.72 & 8.70 & 8.35 & 0.50 & 257 \\
\hline & \multirow{3}{*}{0.65} & 20000 & 8.13 & 9.25 & 8.72 & 0.36 & 151 \\
\hline & & 25000 & 7.86 & 9.25 & 8.54 & 0.69 & 189 \\
\hline & & 30000 & 7.80 & 8.68 & 8.29 & 0.44 & 227 \\
\hline & \multirow{3}{*}{0.7} & 20000 & 8.32 & 9.59 & 9.03 & 0.42 & 133 \\
\hline & & 25000 & 8.15 & 9.39 & 8.86 & 0.62 & 166 \\
\hline & & 30000 & 8.07 & 9.23 & 8.68 & 0.58 & 199 \\
\hline \multirow{9}{*}{240} & \multirow{3}{*}{0.6} & 50000 & 23.10 & 25.80 & 24.21 & 1.22 & 1619 \\
\hline & & 55000 & 23.09 & 25.77 & 24.11 & 1.35 & 1781 \\
\hline & & 60000 & 23.09 & 25.77 & 24.08 & 1.35 & 1943 \\
\hline & \multirow{3}{*}{0.65} & 50000 & 22.54 & 35.33 & 25.16 & 6.05 & 1536 \\
\hline & & 55000 & 22.52 & 34.62 & 25.02 & 6.39 & 1689 \\
\hline & & 60000 & 22.51 & 34.12 & 24.94 & 6.13 & 1843 \\
\hline & \multirow{3}{*}{0.7} & 50000 & 22.68 & 26.32 & 24.30 & 1.63 & 2015 \\
\hline & & 55000 & 22.61 & 26.17 & 24.24 & 1.79 & 2217 \\
\hline & & 60000 & 22.56 & 26.09 & 24.17 & 1.77 & 2418 \\
\hline \multirow{9}{*}{480} & \multirow{3}{*}{0.6} & 80000 & 50.02 & 52.75 & 50.97 & 0.79 & 13869 \\
\hline & & 85000 & 50.01 & 52.73 & 50.89 & 0.82 & 14736 \\
\hline & & 90000 & 50.00 & 52.72 & 50.84 & 0.83 & 15603 \\
\hline & \multirow{3}{*}{0.65} & 80000 & 48.68 & 52.74 & 51.06 & 1.17 & 14917 \\
\hline & & 85000 & 48.63 & 52.71 & 50.96 & 1.16 & 15850 \\
\hline & & 90000 & 48.61 & 52.32 & 50.85 & 1.09 & 16782 \\
\hline & \multirow{3}{*}{0.7} & 80000 & 50.20 & 52.63 & 51.69 & 0.82 & 17270 \\
\hline & & 85000 & 50.19 & 52.55 & 51.59 & 0.79 & 18349 \\
\hline & & 90000 & 50.11 & 52.33 & 51.51 & 0.78 & 19428 \\
\hline
\end{tabular}

for operation periods of 60,240 , and 480 months are used, respectively, to make sure of the GA convergence.

Results of the GA runs including the maximum, minimum, and average solution costs of ten runs using randomly generated initial guesses, standard deviation of the solution, and the $\mathrm{CPU}$ times required to get the solution at different generations for different target reliabilities are shown in Tables 4 and 5 for the hydropower operations, with and without evaporation losses, respectively. The results obtained at different generations are also shown in these tables to demonstrate the convergence of GA. Small standard deviations of the solutions for both cases show that the GA model has converged on its best capacity.

Performance of the proposed ARCA method and that of GA are shown in Table 6 for the case of hydropower operation, without evaporation losses. In the table, the solution costs and the ratio of the computational times required by the GA and ARCA $\left(t_{\mathrm{GA}} / t_{\mathrm{ARCA}}\right)$ are shown for different target reliabilities and operation periods. It is seen that the proposed ARCA model produces solutions $6 \%, 9 \%$, and $8 \%$ 
Table 5. Results of GA for hydropower operation, with evaporation losses, for periods of 60, 240, and 480 months.

\begin{tabular}{|c|c|c|c|c|c|c|c|}
\hline \multirow{2}{*}{$\begin{array}{l}\text { Operation } \\
\text { period }\end{array}$} & \multirow{2}{*}{$\begin{array}{c}\text { Target } \\
\text { reliability }\end{array}$} & \multirow{2}{*}{ Generation } & \multicolumn{3}{|c|}{ Total cost } & \multirow{2}{*}{ SD } & \multirow{2}{*}{$\begin{array}{c}\text { Average computation } \\
\text { time }(\mathrm{sec})\end{array}$} \\
\hline & & & Minimum & Maximum & Average & & \\
\hline \multirow{9}{*}{60} & \multirow{3}{*}{0.6} & 20000 & 9.69 & 11.55 & 10.55 & 0.55 & 229 \\
\hline & & 25000 & 9.62 & 11.49 & 10.45 & 0.93 & 286 \\
\hline & & 30000 & 9.51 & 11.42 & 10.28 & 0.96 & 343 \\
\hline & \multirow{3}{*}{0.65} & 20000 & 10.02 & 11.51 & 10.69 & 0.56 & 246 \\
\hline & & 25000 & 9.93 & 11.44 & 10.63 & 0.76 & 308 \\
\hline & & 30000 & 9.64 & 11.25 & 10.45 & 0.80 & 369 \\
\hline & \multirow{3}{*}{0.7} & 20000 & 9.92 & 11.86 & 11.04 & 0.53 & 225 \\
\hline & & 25000 & 9.91 & 11.78 & 10.91 & 0.93 & 282 \\
\hline & & 30000 & 9.90 & 11.73 & 10.77 & 0.92 & 338 \\
\hline \multirow{9}{*}{240} & \multirow{3}{*}{0.6} & 50000 & 29.37 & 31.68 & 30.57 & 1.03 & 3305 \\
\hline & & 55000 & 28.90 & 32.52 & 30.49 & 1.62 & 3635 \\
\hline & & 60000 & 29.32 & 31.54 & 30.35 & 1.11 & 3966 \\
\hline & \multirow{3}{*}{0.65} & 50000 & 28.69 & 38.10 & 31.10 & 4.37 & 2702 \\
\hline & & 55000 & 28.62 & 37.84 & 30.86 & 4.81 & 2972 \\
\hline & & 60000 & 28.51 & 37.60 & 30.65 & 4.75 & 3243 \\
\hline & \multirow{3}{*}{0.7} & 50000 & 28.90 & 32.52 & 30.49 & 1.62 & 3097 \\
\hline & & 55000 & 28.86 & 32.49 & 30.41 & 1.82 & 3407 \\
\hline & & 60000 & 28.71 & 32.34 & 30.30 & 1.82 & 3716 \\
\hline \multirow{9}{*}{480} & \multirow{3}{*}{0.6} & 80000 & 61.67 & 65.30 & 63.45 & 1.32 & 20314 \\
\hline & & 85000 & 61.66 & 65.07 & 63.29 & 1.20 & 21583 \\
\hline & & 90000 & 61.66 & 64.79 & 63.17 & 1.15 & 22853 \\
\hline & \multirow{3}{*}{0.65} & 80000 & 61.69 & 65.09 & 63.73 & 1.29 & 19384 \\
\hline & & 85000 & 61.68 & 65.00 & 63.61 & 1.25 & 20596 \\
\hline & & 90000 & 61.58 & 64.98 & 63.51 & 1.26 & 21807 \\
\hline & \multirow{3}{*}{0.7} & 80000 & 62.34 & 65.26 & 64.01 & 0.88 & 21379 \\
\hline & & 85000 & 62.30 & 65.08 & 63.85 & 0.82 & 22715 \\
\hline & & 90000 & 62.26 & 64.59 & 63.75 & 0.74 & 24052 \\
\hline
\end{tabular}

cheaper than the solutions obtained by GA with a computational effort 1257,1581 , and 7817 times less than those required by GA for the operation periods of 60,240 , and 480 months, respectively.

Table 7 compares the results obtained by the proposed ARCA method with those of GA considering different target reliabilities for hydropower operation considering evaporation losses. It is again seen that the proposed ARCA model has been able to produce superior solutions to those of GA for all operation periods and all target reliabilities. In fact, the solution produced by the ARCA is on average $5 \%, 12 \%$, and $9 \%$ cheaper than the final solutions obtained by GA with much reduced computational effort for operation periods of 60,240 , and 480 months, respectively. It is interesting to note that the computational effort required by the proposed ARCA model to get a better solution is at least 2000 times less than that required by GA, emphasizing the computational efficiency of the proposed method. 
Table 6. Comparison of the results obtained by GA and ARCA for hydropower operation, without evaporation losses, for periods of 60,240 , and 480 months.

\begin{tabular}{|c|c|c|c|c|}
\hline \multirow[b]{2}{*}{$\begin{array}{c}\text { Operation } \\
\text { period }\end{array}$} & \multirow[b]{2}{*}{$\begin{array}{c}\text { Target } \\
\text { reliability }\end{array}$} & \multicolumn{2}{|c|}{ Total cost } & \multirow[b]{2}{*}{$\begin{array}{c}\left(t_{\mathrm{GA}} /\right. \\
\left.t_{\mathrm{ARCA}}\right)\end{array}$} \\
\hline & & $\begin{array}{c}\text { Best solution } \\
\text { of GA }\end{array}$ & ARCA & \\
\hline \multirow{3}{*}{60} & 0.6 & 7.72 & 7.41 & 1606 \\
\hline & 0.65 & 7.80 & 7.39 & 1261 \\
\hline & 0.7 & 8.07 & 7.38 & 905 \\
\hline \multirow{3}{*}{240} & 0.6 & 23.09 & 21.21 & 1398 \\
\hline & 0.65 & 22.51 & 20.89 & 1396 \\
\hline & 0.7 & 22.56 & 20.76 & 1950 \\
\hline \multirow{3}{*}{480} & 0.6 & 50.00 & 45.99 & 6395 \\
\hline & 0.65 & 48.61 & 45.71 & 7806 \\
\hline & 0.7 & 50.11 & 45.55 & 9251 \\
\hline
\end{tabular}

Table 7. Comparison of the results obtained by GA and ARCA for hydropower operation, with evaporation losses, for periods of 60,240 , and 480 months.

\begin{tabular}{|c|c|c|c|c|}
\hline \multirow[b]{2}{*}{$\begin{array}{l}\text { Operation } \\
\text { period }\end{array}$} & \multirow[b]{2}{*}{$\begin{array}{c}\text { Target } \\
\text { reliability }\end{array}$} & \multicolumn{2}{|c|}{ Total cost } & \multirow[b]{2}{*}{$\begin{array}{c}\left(t_{\mathrm{GA}} /\right. \\
\left.t_{\mathrm{ARCA}}\right)\end{array}$} \\
\hline & & $\begin{array}{c}\text { Best solution } \\
\text { of GA }\end{array}$ & RCA & \\
\hline \multirow{3}{*}{60} & 0.6 & 9.51 & 9.19 & 2144 \\
\hline & 0.65 & 9.64 & 9.18 & 2050 \\
\hline & 0.7 & 9.90 & 9.18 & 1536 \\
\hline \multirow{3}{*}{240} & 0.6 & 29.32 & 25.97 & 2853 \\
\hline & 0.65 & 28.51 & 25.84 & 2457 \\
\hline & 0.7 & 28.71 & 25.80 & 2997 \\
\hline \multirow{3}{*}{480} & 0.6 & 61.66 & 56.72 & 9366 \\
\hline & 0.65 & 61.58 & 56.58 & 10143 \\
\hline & 0.7 & 62.26 & 56.51 & 11453 \\
\hline
\end{tabular}

\section{Conclusions}

A novel cellular automata approach was developed for an efficient and effective solution to reliabilitybased hydropower operation of reservoirs. The method is based on different treatments of the operational and reliability constraints of the problem. A high enough value of the penalty parameter is used for the operational constraints while a lower than enough value is used for the reliability constraint, leading to complete fulfillment of the first set of constraints and partial enforcement of the second set. Since the proper value of the penalty parameter for the reliability constraint is not known a priori, an adaptive method is introduced to find its proper value. For this, the optimal operation problem is first solved using a zero value of penalty parameter and is adjusted considering the reliability of the optimal operation obtained. At each iteration, the penalty parameter decreases if the current reliability is greater than the target reliability and increases otherwise. The proposed method is applied to optimal hydropower operation, for both cases of with and without evaporation losses, of Dez reservoir in Iran considering various target reliabilities for periods of 5,20, and 40 years and the results are presented and compared with those obtained by a GA. The results indicate the superiority of the proposed method to the GA in both efficiency and effectiveness of the method.

\section{References}

1. Arnold, E., Tatjewski, P. and Wolochowicz, P. "Two methods for large-scale nonlinear optimization and their comparison on a case study of hydropower optimization", Journal of Optimization Theory and Applications, 81(2), pp. 221-248 (1994).

2. Zambelli, M.S., Luna, I. and Soares, S. "Long-term hydropower scheduling based on deterministic nonlinear optimization and annual inflow forecasting models", In PowerTech, IEEE Bucharest, pp. 1-8 (2009).

3. Zhao, T., Zhao, J. and Yang, D. "Improved dynamic programming for hydropower reservoir operation", Journal of Water Resources Planning and Management, 140(3), pp. 365-374 (2012)

4. Becker, L. and Yeh, W. "Optimization of real-time operation of a multiple-reservoir system", Water Resour. Res., 10(6), pp. 1107-1112 (1974).

5. Nadala, K.D.W. and Bogardi, J.J. "Dynamic programming based operation of reservoirs: applicability and limits", Cambridge University Press, Cambridge (2007).

6. Braga Jr, B.P., Yen, W.W.G., Becker, L. and Barros, M.T. "Stochastic optimization of multiple-reservoirsystem operation", Journal of Water Resources Planning and Management, 117(4), pp. 471-481 (1991).

7. Archibald, T.W., Mckinnon, K.I.M. and Thomas, L.C. "Modeling the operation of multi reservoir systems using decomposition and stochastic dynamic programming", Naval Res. Logis., 53, pp. 217-225 (2006).

8. Tejada-Guibert, J.A., Johnson, S.A. and Stedinger, J.R. "Comparison of 2 approaches for implementing multi reservoir operating policies derived using stochastic dynamic programming", Water Resource Research, 29, pp. 2139-2153 (1993).

9. Wardlaw, R. and Sharif, M. "Evaluation of genetic algorithms for optimal reservoir system operation", Water Resources Planning and Management. ASCE, 125, pp. 25-33 (1999). 
10. Jothiprakash, V. and Shanthi, G. "Single reservoir operating policies using genetic algorithm", Water Resource Management, 20(6), pp. 917-929 (2006).

11. Cai, X.M., Mckinney, D.C. and Ladon, L.S. "Solving non-linear water management models using a combined genetic algorithm and linear programming approach", Advances in Water Resources, 24, pp. 667676 (2001).

12. Reis, L.F.R., Walters, G.A., Savic, D. and Chaudry, F.H. "Multi reservoir operation planning using hybrid genetic algorithm and linear programming (GA-LP): an alternative stochastic approach", Water Resource Management, 19, pp. 831-848 (2005).

13. Jalali, M.R., Afshar, A. and Marino, M.A. "Reservoir operation by ant colony optimization algorithms", Iran J. Scitechnol Trans B-Eng., 30(B1), pp. 107-117 (2006).

14. Kumar, D.N. and Reddy, M.J. "Ant colony optimization for multipurpose reservoir operation", Water Resource Management, 20(6), pp. 879-898 (2006).

15. Kumar D.N. and Reddy, M.J. "Multipurpose reservoir operation using particle swarm optimization", Water Resource Planning and Management, 133(3), pp. 192201 (2007).

16. Teegavarapu, R.S.V. and Simonovic, S.P. "Optimal operation of reservoir systems using simulated annealing", Water Resource Management, 16(5), pp. 401-428 (2002).

17. Georgiou, P.E., Papamichali, D.M. and Vougioukas, S.G. "Optimal irrigation reservoir operation and simultaneous multi-crop cultivation area selection using simulated annealing", Irrig Drain, 55(2), pp. 129-144 (2006).

18. Afshar, A., Bozorg Haddad, O., Marino, M.A. and Adams, B.J. "Honey-bee mating optimization (HMBO) algorithm for optimal reservoir operation", Journal of the Franklin Institute, 344, pp. 452-462 (2007).

19. Singh, A. "An overview of the optimization modeling applications", Journal of Hydrology, 466, pp. 167-182 (2012).

20. Afshar, M.H. and Shahidi, M. "Optimal solution of large-scale reservoir operation problems: Cellular Automata versus heuristic search methods", Engineering Optimization, 41, pp. 275-293 (2009).

21. Askew, A.J. "Optimum reservoir operating policies and the imposition of a reliability constraint", Water Resource Research, 10, pp. 51-56 (1974).

22. Sniedovich, M. "Reliability-constrained reservoir operation control problems: 1. Methodological issues", Water Resource Research, 15, pp. 1574-1582 (1979).

23. Simonovic, S.P. and Marino, M.A. "Reliability programming in reservoir management: 1 . Single Multipurpose reservoir", Water Resource Research, 16, pp. 844-848 (1980).
24. Simonovic, S.P. and Marino, M.A. "Reliability programming in reservoir management: 3. System of multipurpose reservoirs", Water Resource Research, 18, pp. 735-743 (1982).

25. Marino, M.A. and Mohammadi, B. "Reservoir management: A reliability programming approach", Water Resource Research, 19, pp. 613-620 (1983).

26. Sreenivasan, K.R. and Vedula, S. "Reservoir operation for hydropower optimization: a chance-constrained approach", Sadhan-Academy Proceedings in Engineering Sciences, 21, pp. 503-510 (1996).

27. Ulam, S.M. "Random process and transformations", Proceedings of the International Congress of Mathematics, 2, pp. 264-275 (1952, held in 1950).

28. Thatcher, J. "Universality in the von Neumann cellular model", Technical Report, 03105-30-T, University of Michigan (1964).

29. Codd, E.F., Cellular Automata, Academic Press, New York (1968).

30. Burks, E., Essays on Cellular Automata, University of Illinois press, Champaign, IL (1972).

31. Marin, M., Rojas-Molina, V., Lopez-Cajun, C.S., Herrera, A. and Castano, V.M. "Cellular automata simulation of dispersion of pollutants", Journal of Computational Materials, 18, pp. 132-140 (2000).

32. Packard, N.H. "Lattice models for solidification and aggregation", In: S. Wolfram, ed., Theory and Applications Cellular Automata, Singapore: World Scientific Publications, pp. 305-310 (1986).

33. Chopard, B., Droz, M., Cornell, S. and Frachebourg, L. "Cellular automata approach to reaction-diffusion system: Theory and application", Cellular Automata Prospects in Astrophysical Applications, pp. 157-186 (1993).

34. Chopard, B., Droz, M. and Kolb, M. "Cellular automata approach to non-equilibrium diffusion and gradient percolation", Journal of Physics A: Mathematical and General, 22, pp. 1609-1619 (1989).

35. Liu, F. and Goldenfeld, N. "Genetic features of latestage crystal growth", Physical Review A, 42, pp. 895903 (1990).

36. Sentos, R.M.Z.D. and Coutinho, S. "Dynamic of HIV approach: A cellular automata approach", Physical Review Letter, 87(16), pp. 102-104 (2001).

37. Chen, Q., Ye, F. and Li, W. "Cellular-automata-based ecological and eco-hydraulics modeling", Journal of Hydroinformatics, 11(3-4), pp. 252-265 (2009).

38. Li, R., Qiuwen, C. and Fei, Y. "Modelling the impacts of reservoir operations on the downstream riparian vegetation and fish habitats in the Lijiang River", Journal of Hydroinformatics, 13(2), pp. 229-244 (2011).

39. Ghimire, B., Chen, A.S., Guidolin, M., Keedwell, E.C., Djordjević, S. and Savić, D.A. "Formulation of a fast 2D urban pluvial flood model using a cellular automata approach", Journal of Hydroinformatics, 15(3), pp. 676-686 (2013). 
40. Austin, R.J., Chen, A.S., Savić, D.A. and Djordjević, S. "Quick and accurate Cellular Automata sewer simulator", Journal of Hydroinformatics, 16(6), pp. 13591374 (2014).

41. Sanchez, A., Neiler, M., Zoran, V. and Roland, P. "An integrated cellular automata evolutionarybased approach for evaluating future scenarios and the expansion of urban drainage networks", Journal of Hydroinformatics, 16(2), pp. 319-340 (2014).

42. Kita, E. and Toyoda, T. "Structural design using cellular automata", Struct. Multidiscip. Optim., 19, pp. 64-73 (2000).

43. Tatting, B. and Gürdal, Z. "Cellular automata for design of two-dimensional continuum structures", 8 th Proc. of AIAA/NASA/ISSMO. Symp. on Multidisc. Anal. And Optim, California, USA, pp. 1-10 (2000).

44. Afshar, M.H. and Faramarzi, A. "Size optimization of truss structures by cellular automata", Journal of Computer Science and Engineering, 3.1, pp. 1-9 (2010).

45. Faramarzi, A. and Afshar, M.H. "A novel hybrid CA-LP approach for the optimal sizing of planar truss structures", Journal of Civil Engineering and Environmental Systems (2012).

46. Faramarzi, A. and Afshar, M.H. "Application of cellular automata to size and topology optimization of truss structures", Scientia Iranica, 19(3), pp. 373-380 (2012).

47. Keedwell, E. and Khu, S.T. "A hybrid genetic algorithm for the water distribution networks", Journal of Engineering Application of Artificial Intelligence, 18, pp. 461-472 (2005).

48. Guo, Y., Keedwell, E.C., Walters, G.A. and Khu, S.T. "Hybridizing cellular automata principles and NSGII for multi-objective design of urban water networks", Computer Science and Mathematics, 44(3), pp. 546559 (2007a).

49. Guo, Y., Walters, G.A., Khu, S.T. and Keedwell, E.C. "A novel cellular automata based approach to optimal storm sewer design", Engineering Optimization, 39(3), pp. 345-364 (2007b).

50. Afshar, M.H. "A cellular automata approach for the hydro-power operation of multi-reservoir systems", Proceedings of the Institution of Civil Engineers-Water Management, 166(9), pp. 465-478 (2013).
51. Afshar, M.H., Shahidi, M., Rohani, M. and Sargolzaei, M. "Application of cellular automata to sewer network optimization problems", Scientia Iranica, 18(3), pp. 304-312 (2011).

52. Afshar, M.H. and Rohani, M. "Optimal design of sewer networks using cellular automata-based hybrid methods: Discrete and continuous approaches", Engineering Optimization, 44(1), pp. 1-22 (2012).

\section{Biographies}

Mohammad Azizipour received his BS degree in Civil Engineering from Shahid Chamran University, Ahwaz, Iran, in 2008, and his MS degree in Water Engineering from the same university in 2010. He is currently senior $\mathrm{PhD}$ student in Water Resources Management.

Mohammad Hadi Afshar received his BS degree from the Engineering Faculty at Tehran University, Iran, in 1984, and his MS and $\mathrm{PhD}$ degrees from the University College of Swansea, UK, in 1989 and 1993, respectively, all in Civil Engineering. He is currently Associate Professor of Civil Engineering at Iran University of Science and Technology.

Dr. Afshar worked as part-time researcher with Mahab Ghods Consulting Engineers from 1996 to 1999, where he managed two important research projects on the Pashakola Dam Break and Wave Energy Estimation in the Chahbahar region. Moreover, he has managed eleven research projects on the optimal design of water distribution networks, sewer networks, pipeline systems, flood controlling systems, reservoir operation, spillway flow, and spillway design, leading to the development of OPTNET software for the optimal design of water distribution networks.

Dr. Afshar is author or coauthor of over 90 research articles published in national and international journals and 70 conference papers, and has translated several books into the Persian language. He has also supervised about 40 postgraduate students, three of whom are $\mathrm{PhD}$ candidates. His research interests include mathematical modeling and optimization in hydraulic structures and water engineering. 